\title{
Promoting self-management, health literacy and social capital to reduce health inequalities in older adults living in urban disadvantaged areas: protocol of the randomised controlled trial AEQUALIS
}

\author{
Laura Coll-Planas ${ }^{1,2^{*}}$ (D), Sergi Blancafort ${ }^{1,2}$, Xavier Rojano $^{1,2}$, Marta Roqué ${ }^{1,2}$
} and Rosa Monteserín 2,3

\begin{abstract}
Background: Older people living in socio-economic deprived urban areas especially suffer the effects of health inequalities but have been insufficiently targeted. Strategies promoted by local primary health care agents might influence health and social behaviours as intermediate social determinants that are modifiable and thus can potentially mitigate health inequalities.

Therefore, we aim to develop and assess the effectiveness of a complex intervention based on a community programme that promotes self-management, health literacy and social capital targeting older people from urban socioeconomically disadvantaged areas in order to improve their self-perceived health as an indicator of health inequality reduction.

Methods/design: Design: A pragmatic multicentre, parallel, randomised controlled trial will be implemented in 16 primary health care centres from six urban areas in neighbourhoods with low-socioeconomic level. Target: communitydwelling aged 60 years or above who perceive their health as fair or poor.

The programme is called "Sentir-nos Bé" ("Feeling well") and comprises 12 two-hour sessions held once a week in groups of 12-15 people. Group dynamics are designed to promote mutual support, social participation and new knowledge on health literacy and self-management, resulting in meaningful changes in their daily life that positively affect their health and wellbeing.

A sample size of 390 participants, randomised to the intervention or the control group, will be needed to detect a clinically relevant benefit in the primary outcome self-perceived health after 3-month intervention. A follow-up will be conducted at 9 months post-intervention. Participants in the control group will receive usual care and remain in a waiting-list to join the programme once the trial ends. A process evaluation will provide greater confidence in the conclusions about the effectiveness of the intervention. Ethics approval: Clinical Investigation Ethics Committee of the IDIAP Jordi Gol (P15/031). Dissemination: Findings will be disseminated through conference presentations and openaccess journals.

\footnotetext{
* Correspondence: laura.coll@uab.cat

${ }^{1}$ Fundació Salut i Envelliment UAB (Universitat Autònoma de Barcelona), Casa

Convalescència. Sant Antoni Maria Claret 171, 4a planta, 08041 Barcelona,

Spain

${ }^{2}$ Institute of Biomedical Research (IIB Sant Pau), Barcelona, Spain

Full list of author information is available at the end of the article
} 
(Continued from previous page)

Discussion: The project will promote the implementation of evidence-based intervention procedures in future health policy strategies targeting older people while considering the social aspects of inequality.

Trial registration: NCT02733523. Retrospectively registered. Date of registration: April 11, 2016.

Keywords: Social medicine, Public health, Primary care

\section{Background}

The most disadvantaged socioeconomic groups have generally poorer health status [1]. Cities are the territories that concentrate higher health inequalities and ageing and gender are axes of inequality [2]. Lastly, there is a worldwide demographic shift towards a more aged society and towards urbanization [3]. Therefore, older people living in socio-economic deprived urban areas should be a specific focus for health inequality policies since they especially suffer its effects.

Despite the growing attention on health inequalities since 1980s, and the progress made in the last years in the development of policies and interventions to reduce them, strategies to reduce health inequalities are heterogeneously implemented and the group of older people has been insufficiently targeted [4].

Current evidence is strong in explaining the contribution of specific factors to health inequalities but not on the effectiveness of policies and interventions to reduce them, since it does not often fulfil the highest scientific standards. Consequently, more rigorous evidence-based approaches are needed to inform policymaking in this area [5]. In this respect, the emerging methodologies that address complex interventions could be valuable [6].

It has been raised that focusing on intermediate effects of interventions that target indicators such as the prevalence of health determinants can be useful to reach the WHO goal of reducing health inequalities by $25 \%[7,8]$. In this vein, self-perceived health could be a useful indicator since it correlates with general health status, mortality and morbidity, as well as health inequalities [911]. Likewise, health promotion and salutogenesis emphasize the need to improve the perception of health, along with wellbeing and quality of life $[12,13]$.

It is acknowledged that the reduction of socioeconomic inequalities in health requires comprehensive strategies with sustained actions addressing social determinants of health instead of isolated actions. Innovative strategies have been identified as effective in five policy areas: policy steering mechanisms, labour market and working conditions, territorial approaches, consumption and health-related behaviour and health care. Hence, two main strategies have been defined: addressing upstream factors with actions related to income, employment and education, and addressing downstream factors with health-related actions targeting health-related behaviours such as food consumption, smoking, and physical exercise. Healthy lifestyles can be promoted by universal and targeted approaches. Targeted approaches can be part of more general strategies and can be directed towards specific groups in terms of age, sex and other sociodemographic characteristics such as living in lower socioeconomic conditions [5].

Promoting self-care habits to increase healthy nutrition and physical activity among socioeconomically disadvantaged older people should contribute to reducing their increased risk of morbidity, mortality and disability related with health inequalities [14]. Likewise, adopting measures to improve personal and community health has been linked with the level of knowledge, personal skills and confidence. Accordingly, health literacy has been defined as the cognitive and social skills that determine the motivation and ability of individuals to gain access, understand and use information in ways that promote and maintain good health [15]. Low health literacy is related with poor participation in preventive and health promotion activities, worse chronic disease self-management, an increase of hospital stays, and higher mortality and morbidity [16]. Therefore, specific interventions to increase health literacy could contribute to self-care habits.

Accordingly, despite social determinants of health are mainly outside the health care system, healthrelated actions such as interventions promoted by local primary health care agents may be of special interest to influence intermediate determinants of health inequalities that are potentially modifiable such as health-related behaviours, i.e., self-care habits and health literacy [17].

Additionally, social capital is considered a social determinant of health, cross-cutting the structural and intermediary determinants, with features linked to both [18-20]. Thus, strengthening social capital has been also included in comprehensive packages of policies and interventions to reduce inequalities in health [21]. Nevertheless, there are controversies on the definition of social capital and its implications on health inequalities. In this study, social capital follows Putnam's approach [22] and is defined according to the conceptual model developed by Islam and adapted to ageing by Nyqvist [23] as an umbrella concept that includes 
individual (family and friends) and collective (community) social resources, as well as structural (social networks, contacts and participation) and subjective (social support and sense of belonging) aspects. Several observational studies have shown social capital components as consistent protective health factors regarding a variety of outcomes such as mortality and selfperceived health [24, 25]. Whereas the evidence from randomized controlled trials assessing health effects of social capital interventions is still uncertain but promising [26]. Thus, social capital could be part of a multicomponent strategy to address health inequalities.

Finally, social capital components, self-care and health literacy could reinforce each other reaching synergistic effects on health outcomes, e.g., social support increases self-care while health literacy is associated with healthier habits and higher social participation [26]. Accordingly, after an initial intervention design based on these three pillars, a pilot study was conducted to explore the feasibility of the intervention, the recruitment strategy and evaluation [27].

\section{Rationale of the study}

There is a need to build new intervention strategies based on modifiable intermediate factors to reduce health inequalities. The design of these strategies should consider the synergistic effects of self-care, social capital and health literacy. The effectiveness of these interventions should be robustly assessed considering their complexity to build an evidence-base for public health policy and practice.

Therefore, we aim to develop and assess the effectiveness of an intervention designed to promote selfmanagement, health literacy and social capital targeting older people from urban socioeconomically disadvantaged areas who perceived their health as fair or poor in improving their self-perceived health as indicator of reducing health inequalities.

Secondarily, we will assess the effectiveness of the intervention in the improvement of self-management, health literacy and social capital (i.e., social support and social participation), health-related quality of life, loneliness, depressive symptoms and psychological well-being. In addition, the effectiveness of the intervention will be assessed on specific subgroups: women, oldest people, and people with lowest educational and socioeconomic levels. Finally, we aim to identify profiles of participants according to their patterns of health behaviours, health literacy and social capital, considering gender, educational and socioeconomic level and contextual factors, and we will explore whether and how these profiles respond to the intervention.

\section{Methods and analysis}

\section{Study design and setting}

To achieve these objectives, a pragmatic multicentre, parallel, randomised controlled trial (RCT) will be carried out. The study protocol adheres to the SPIRIT recommendations [28]. The trial will be implemented in 16 primary health care centres (PCC) from six urban areas. We have prioritized neighbourhoods with lowsocioeconomic levels with established community programmes to reduce health inequalities $[29,30]$.

\section{Participants}

Participants are eligible if: they are community-dwelling aged 60 years or above and perceive their health as fair or poor. Screening on self-rated health will be performed through the first item of the SF-36 questionnaire: "In general, would you say your health is: (1) Excellent, (2) Very Good, (3) Good, (4) Fair or (5) Poor".

Participants will be excluded if: they need help to go to the PCC; have cognitive impairment or diagnosed dementia; have a medical condition that contraindicates physical activity; have any severe mental health problem that hinders participation in a group dynamic; have an end-of-life situation.

\section{Recruitment}

PCC of the prioritized neighbourhoods are contacted to offer their involvement in the programme. The research team will inform the whole team about the background, the aims of the study, eligibility criteria and the recruitment strategy.

Professionals from PCC will be selected on a voluntary basis to collaborate as outcome assessors or observers of the intervention. Each PCC is committed to recruit 30 participants. Professionals can identify potential participants in routine visits or actively calling known patients that might fulfil eligibility criteria. As additional recruitment strategies, posters and videos are displayed in the PCC advertising the study. A professional from the PCC will explain the trial to interested patients and screen for the eligibility criteria. Those participants who fulfil the criteria and agree to participate will be given the information sheet about the study and the informed consent.

\section{Randomisation and blinding}

Participants who sign the informed consent will be scheduled for the baseline assessment. Once the participant has been included in the study, assigned an identification code, and has completed the study baseline assessment, the participant will be randomised to one of the two study groups: intervention and control group (fig. 1). Concealed randomisation will be conducted centrally at FSiE-UAB, using a computer-based random-block randomisation scheme, stratified by 


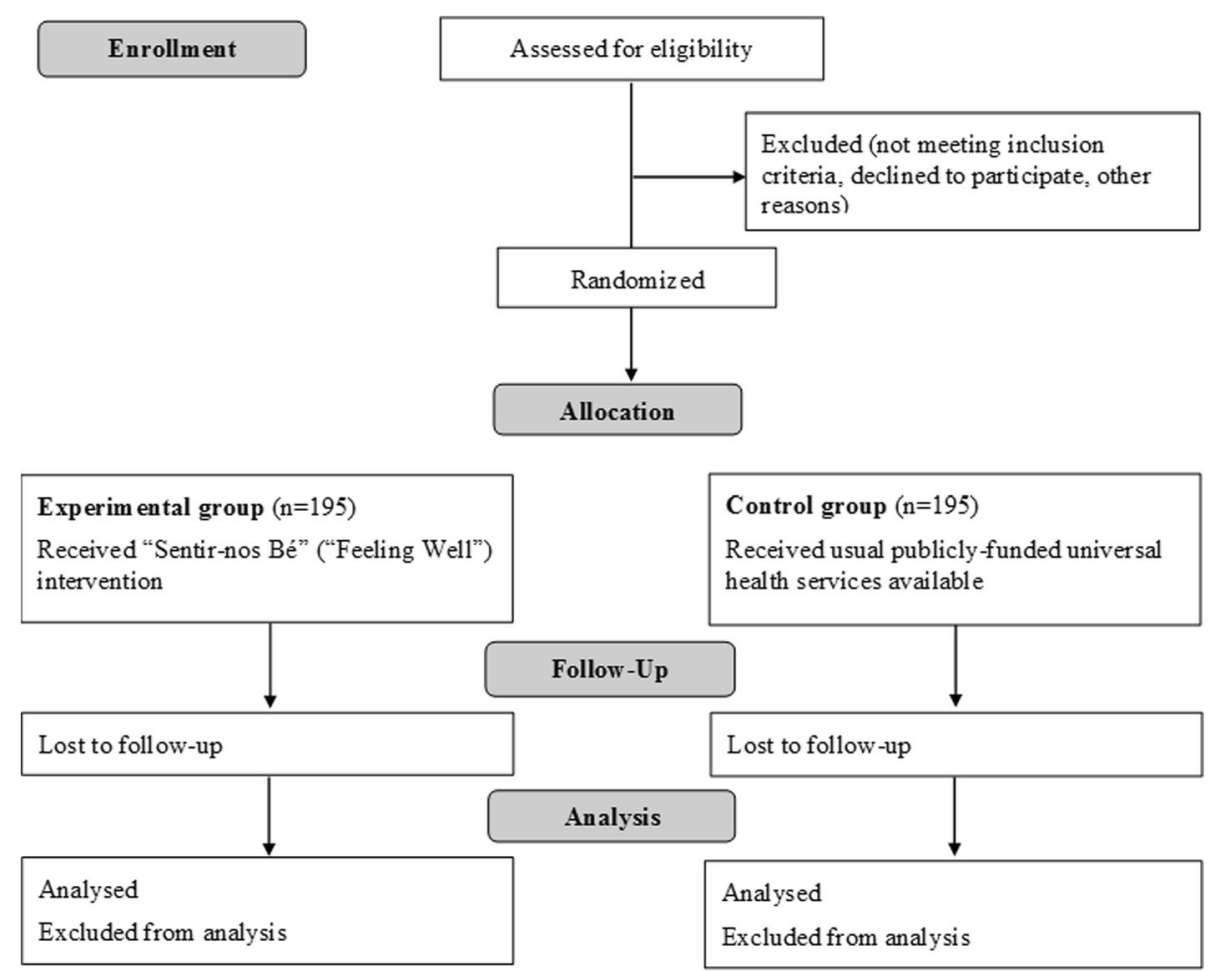

Fig. 1 Trial Consort flow diagram

PCC. In each PCC, one experimental group and one control group will be set up. Participants and professionals conducting the group-based intervention will remain unblinded, likewise participants can easily reveal their group allocation and thus blinding outcome assessors would be hard to sustain.

\section{Interventions}

\section{Experimental group}

The intervention is a community program with multiple components, thus a complex intervention. A feasibility study was conducted to test the initial intervention design and the intervention was optimized for the full trial accordingly [27]. The final intervention is described in accordance with the TIDieR guidelines below and in the Table 1 [31].

The programme is called "Sentir-nos Bé" ("Feeling well") and it is aimed at promoting social support and participation (i.e., social capital), self-management and health literacy as intermediate factors between social determinants and health outcomes with potential to mitigate health inequalities. The conceptual framework of the intervention is described in fig. 2 .

The intervention methodology will be participatory with the purpose to promote the empowerment among participants. Group dynamics are designed to promote mutual knowledge and support, trust among participants, exchange of personal experiences among peers and the acquisition of new knowledge related to health literacy and selfmanagement in order to lead to behavioural changes in their daily life that are meaningful for them and that positively affect their health and wellbeing. Health and social care professionals (five nurses, two social workers and two general practitioners) with experience working in the PCC will be previously trained as group facilitators by the research team during a two-day workshop. The training is based on how to apply the intervention guide.

The intervention consists in 12 sessions that are held weekly for $2 \mathrm{~h}$ and facilitated in groups of 12 to- 15 people. The programme will be delivered in publicly funded PCC and in different locations of the neighbourhood. Specifically, nine of the 12 sessions will be delivered in the centre, and three sessions consist on local trips and are delivered in: a public space where to practice physical activity (park or pedestrian paths), a supermarket or a market and a community asset that offers social activities that can be of interest to the participants.

The intervention guide sets up a frame for the facilitators to conduct the group dynamics following common principles specified in a decalogue and an homogenous structure, while considering participants' experiences, values and expectations. For example, several activities conducted as a group are highly personalized such as goal setting to change a daily habit to feel better, bringing 
Table 1 Sessions, contents, materials and procedures of "Sentir-nos Bé" community programme

\begin{tabular}{|c|c|c|}
\hline Session number & Contents & Materials and procedures \\
\hline 1 & Health and self-care & $\begin{array}{l}\text { The instructor presents the programme to the participants and they introduce } \\
\text { themselves to the group. Using photos of daily activities related to self-care, } \\
\text { participants share judgements, views and ideas about self-care. Participants } \\
\text { are invited to bring a personal object from home in the next session to } \\
\text { introduce themselves. At the end of each session, participants create cooperatively } \\
\text { a board with paintings, handcrafts, small writings and thoughts, etc. }\end{array}$ \\
\hline 2 & Physical activity & $\begin{array}{l}\text { Participants explain briefly to the group the personal object brought from home. } \\
\text { Participants set and share a specific goal related with their daily life to be fulfilled } \\
\text { during the week. Using local maps, participants identify and share physical activity assets, } \\
\text { discuss about benefits and limitations of doing physical activity and agree on a } \\
\text { group walk in the neighbourhood for the next session. }\end{array}$ \\
\hline 3 & First local trip & $\begin{array}{l}\text { The group does a round walk starting and ending at the primary care centre visiting } \\
\text { interesting places where to do physical activity, e.g., parks or outdoor gyms. }\end{array}$ \\
\hline 4 & Emotional health & $\begin{array}{l}\text { Participants share the fulfilment of their personal goal. If they do not succeed, } \\
\text { the instructor carries out a problem solving technique (each session until the end } \\
\text { of the programme, excepting the local trips). The group discusses and shares strategies } \\
\text { to cope with emotions and feelings. A relaxation technique practice is carried out. }\end{array}$ \\
\hline 5 & Healthy eating habits & $\begin{array}{l}\text { Participants share their nutritional habits and tips to eat cheaper and healthier. } \\
\text { The group shares and discusses about the places in the neighbourhood where } \\
\text { they normally buy. Participants agree upon the market or the supermarket to } \\
\text { visit in the next session. }\end{array}$ \\
\hline 6 & Second local trip & $\begin{array}{l}\text { The group visits a local market or supermarket. During the visit, participants } \\
\text { share and discuss about their habits and preferences when buying. The instructor } \\
\text { and the observers give advice about nutritional facts and reading labels. }\end{array}$ \\
\hline 7 & Loneliness and social relationships & $\begin{array}{l}\text { Using a variety of photos, participants share their thoughts and perceptions about } \\
\text { loneliness and social relationships. The group splits into subgroups that are asked to } \\
\text { create a story based on key words related with social relationships. }\end{array}$ \\
\hline 8 & Participation in the community & $\begin{array}{l}\text { A participant reads out loud the story of "La Lita", an old woman engaged in the } \\
\text { community of a low socio-economic neighbourhood. Using local maps, } \\
\text { participants identify and share community assets, discuss about benefits and } \\
\text { limitations of social participation and agree upon a group visit to a local community } \\
\text { asset for the next session. }\end{array}$ \\
\hline 9 & Third local trip & $\begin{array}{l}\text { The group visits a community asset. A volunteer from the centre explains to the group } \\
\text { the activities carried out. Participants are invited to engage in social activities. }\end{array}$ \\
\hline 10 & Personal autonomy & $\begin{array}{l}\text { The group shares their thoughts and beliefs about personal autonomy discussing } \\
\text { practical cases presented by the instructor. }\end{array}$ \\
\hline 11 & Communication with health professionals & $\begin{array}{l}\text { The group watches four short videos that explain how to prepare the medical encounter. } \\
\text { Participants share and discuss their thoughts and feelings when visiting a health professional, } \\
\text { as well as their personal knowledge about health and social resources. }\end{array}$ \\
\hline 12 & Group discussion & $\begin{array}{l}\text { The group shares and discusses their thoughts and feelings about the programme. } \\
\text { Participants are invited to make an imaginary gift to someone else from the group. } \\
\text { The group shares a farewell meal. }\end{array}$ \\
\hline
\end{tabular}

personal belongings to introduce themselves and making an imaginary gift to another participant. Within the participatory approach, the locations of the three local trips are chosen and agreed by the group based on previous sign posting and mapping of local community assets, thus allowing a tailoring to specific interests and preferences of each group, as well as to the local context.

One or two health or social care professionals from the PCC will be observers of the intervention. They will complete an observation log including quantitative and qualitative measures of implementation such as fidelity and adherence.

\section{Control group}

During the study, the participants from the waiting-list control group will receive the usual publicly funded universal healthcare services available to all population. At the end of the study, these participants will be offered the "Sentir-nos
Bé" programme as a compensation for their time spent being assessed.

\section{Outcomes}

Assessments will be conducted by health or social care professionals from the PCC who are not involved with the intervention delivery or observation. All outcome assessors will receive training in interview skills and outcome measure administration by the PI prior to the start. Outcomes will be measured at the following time points: baseline $\left(T_{0}\right)$, after the intervention is completed $\left(T_{1}\right)$ and 9 months after the end of the intervention $\left(T_{2}\right)$.

\section{Primary outcome}

The primary outcome of the study is self-perceived health and will be estimated through the first item of the SF-36 questionnaire considering good self-rated health if they answer (1) Excellent, (2) Very Good or 


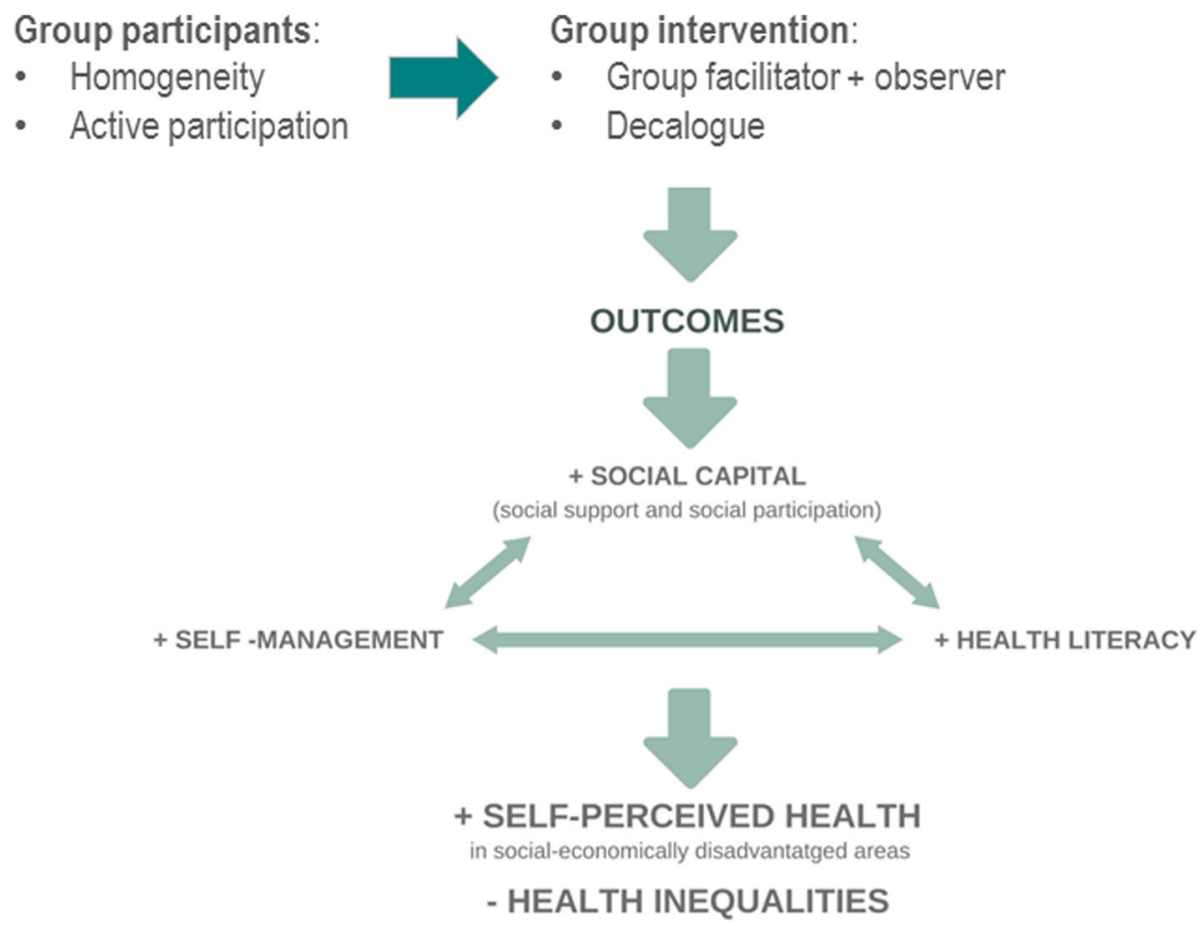

Fig. 2 Conceptual framework of the intervention

(3) Good, and bad self-rated health if they answer (4) Fair or (5) Poor.

For an overview of primary and secondary outcomes, outcomes measures, instruments and assessments time points, see Table 2 .

\section{Sample size}

A sample size of 390 participants, randomised to the intervention or the control group of 195 participants, will be needed to detect a clinically relevant benefit in self-perceived health after 3-month intervention. Selfperceived health is dichotomized as good health (including excellent, very good and good) and poor health (including fair and poor). The clinically relevant change has been defined as a $10 \%$ increase in the prevalence of participants who consider their health as good. The sample size has been estimated on a statistical power of $80 \%$, a significance level of $95 \%$, and an estimated dropout rate of $20 \%$. A prevalence of $20 \%$ of bad self-perceived health in the ESCA 2012 in socio-economic class IVa was considered [32]. The calculations were performed with the "ene 3.0" programme.

\section{Data collection}

Data collected during the study period will include a questionnaire completed by a face-to-face interview with a researcher at baseline, post-intervention and follow-up points. The time for completion will be documented. Participants will be contacted by telephone prior to each follow-up point, to arrange a convenient time for completion with the researcher. All patient data will be kept in strict confidence and managed in accordance with the Spanish Data Protection Organic Law 1999. The data will be stored for 5 years after the end of the study. Following completion of the trial, a cleaned anonymised data set will be shared on request. A complete schedule of enrolment, interventions and assessments times is provided on Table 3.

\section{Data analysis}

Reporting of the results will follow the CONSORT guidelines for randomised controlled trials [33].

First of all, a descriptive analysis will be conducted to characterize the intervention and the control group regarding socio-demographic, health and psychosocial variables.

The efficacy analysis will assess changes in the primary and secondary outcomes between the baseline and 3 months assessments comparing study arms (experimental and control group) with mixed linear models with repeated measures. Linear models will be used to adjust for covariables of interest, specially to correct differences between arms in the baseline characteristics, if applicable.

A diagonal matrix design will be considered for the between-participants covariance matrices (covariance structure for random factors). The between-participants correlations induced by the group delivery of intervention will be taken into account in the models. 
Table 2 Overview of outcomes, outcome measures, instruments and assessments time points

\begin{tabular}{|c|c|c|c|}
\hline Outcomes & Outcome (measures) & Instrument & Assessment time points \\
\hline \multirow[t]{2}{*}{ Personal information } & $\begin{array}{l}\text { Age, gender, living arrangement, civil status, } \\
\text { place of birth, educational background, } \\
\text { job, medical conditions }\end{array}$ & $\begin{array}{l}\text { Primary care records } \\
\text { Self-report }\end{array}$ & $\mathrm{T}_{0}$ \\
\hline & Changes in living arrangement and civil status & & $\mathrm{T}_{1}, \mathrm{~T}_{2}$ \\
\hline Primary outcomes & Health status & $\begin{array}{l}\text { SF-12 } \\
\text { EQ-5D visual analog scale }\end{array}$ & $T_{0}, T_{1}, T_{2}$ \\
\hline \multirow[t]{11}{*}{ Secondary outcomes } & Quality of life & SF-12 & $T_{0}, T_{1}, T_{2}$ \\
\hline & Social capital & European Values Survey & $T_{0}, T_{1}, T_{2}$ \\
\hline & Social support & Inventory of social resources in the elderly & $T_{0}, T_{1}, T_{2}$ \\
\hline & Social participation & Loneliness Este II Scale-Subjective Social Participation Index & $T_{0}, T_{1}, T_{2}$ \\
\hline & Care and self-care & $\begin{array}{l}\text { Self-care semFYC survey } \\
\text { Appraisal of Self-Care Agency Scale }\end{array}$ & $T_{0}, T_{1}, T_{2}$ \\
\hline & Emotional well-being & Warwick-Edinburgh Mental Wellbeing Scale (WEMWBS) & $T_{0}, T_{1}, T_{2}$ \\
\hline & Loneliness & $\begin{array}{l}\text { Gierveld and De Jong scale } \\
\text { Social support perception scale }\end{array}$ & $T_{0}, T_{1}, T_{2}$ \\
\hline & Depression & Geriatric depression scale (GDS-5) & $T_{0}, T_{1}, T_{2}$ \\
\hline & Physical activity & The International Physical Activity Questionnaire (IPAQ) & $T_{0}, T_{1}, T_{2}$ \\
\hline & Health literacy & Health literacy scale (HLS-EU-16) & $T_{0}, T_{1}, T_{2}$ \\
\hline & $\begin{array}{l}\text { Medication consumption } \\
\text { Use of social and health resources }\end{array}$ & $\begin{array}{l}\text { Primary care records } \\
\text { Self-report }\end{array}$ & $T_{0}, T_{1}, T_{2}$ \\
\hline
\end{tabular}

Table 3 Schedule of enrolment, interventions, and assessments

\begin{tabular}{|c|c|c|c|c|c|c|}
\hline \multicolumn{7}{|c|}{ STUDY PERIOD } \\
\hline \multirow[b]{2}{*}{ TIMEPOINT } & \multirow{2}{*}{$\begin{array}{c}\text { Enrolment } \\
-t_{x}\end{array}$} & \multirow{2}{*}{$\begin{array}{c}\text { Pre-allocation } \\
t_{0}\end{array}$} & \multirow{2}{*}{$\begin{array}{c}\text { Allocation } \\
0\end{array}$} & \multicolumn{2}{|c|}{ Post-allocation } & \multirow{2}{*}{$\begin{array}{c}\begin{array}{c}\text { Post- } \\
\text { assessment }\end{array} \\
t_{x}\end{array}$} \\
\hline & & & & $t_{1}$ & $t_{2}$ & \\
\hline \multicolumn{7}{|l|}{ Enrolment } \\
\hline Eligibility screen & $\mathrm{x}$ & & & & & \\
\hline Informed consent & $x$ & & & & & \\
\hline Allocation & & & $x$ & & & \\
\hline \multicolumn{7}{|l|}{ Interventions } \\
\hline \multicolumn{7}{|l|}{ Experimental } \\
\hline \multicolumn{7}{|l|}{ Control } \\
\hline \multicolumn{7}{|l|}{ Assessments } \\
\hline \multirow{2}{*}{$\begin{array}{l}\text { Baseline variables } \\
\text { Post-intervention } \\
\text { and follow-up } \\
\text { variables }\end{array}$} & & $x$ & & & & \\
\hline & & & & $x$ & $x$ & \\
\hline
\end{tabular}


Further testing of the study hypotheses will be conducted through covariance analyses, including in the model relevant covariates (age, gender, educational and socioeconomic levels), and effect modifiers. Estimates of effect will be computed for planned subgroups on age, gender, educational and socioeconomic levels and will be interpreted with caution as exploratory rather than definitive results.

It will follow the intention-to-treat principle, thus including all randomized participants with a baseline assessment regardless of their permanence in the study or their loss to follow-up, withdrawal or drop-out. Furthermore, sensitivity analyses will be conducted. In the first place, a 'per protocol' analysis will comprise all participants with no protocol violations and complete data in the measurements of the primary variables at baseline, end of treatment and follow-up. In a second sensitivity analysis, primary variables with a substantial number of missing values (higher than $5 \%$ ) will be imputed.

All statistical analyses will use two-sided tests of statistical significance; estimates of the size of treatment effects will be presented with confidence intervals and significance tests. Significance levels will be set to a 5\% level, applying the Bonferroni correction to adjust for type I error criteria. All analyses will be performed with SPSS version 20 .

\section{Process evaluation}

AEQUALIS follows the guidance on "Process evaluation of complex interventions" from the Medical Research Council (MRC) for conducting the process evaluation of the study [34].

The process evaluation of the full trial is aimed at providing greater confidence in conclusions about effectiveness of the intervention by assessing: (a) implementation, i.e., the quantity and quality of what was delivered regarding the community programme; (b) the role of context to understand the generalizability of the results (c) the mechanisms of impact.

Methodologically, quantitative measures of implementation such as fidelity and adherence will be combined with qualitative data focused on implementation challenges, mechanisms of impact and context. Qualitative procedures will comprise: participant observation of a variety of sessions, focus groups with the participants of all intervention groups at the end of the programme, interviews with a purposeful sample of participants with different profiles and follow-up and closing meetings with each team of professionals in charge of facilitate and observe the sessions. Interviews and focus groups will be audio recorded and transcribed. The Framework Method will be applied to conduct a content analysis of the qualitative data [35].

\section{Ethics and dissemination}

This study has been approved by the Clinical Investigation Ethics Committee of the IDIAP Jordi Gol (P15/ 031). The Committee will be notified of all substantial modifications to the protocol. The study protocol is registered at ClinicalTrials.gov with the reference number: NCT02733523. Participation is voluntary and all participants will be asked to sign informed consent before the start of the study. At the end of the study, control group participants will be offered the intervention.

One of the tangible products of the study is the intervention guide that facilitates the replication and design of similar interventions, and it can be adapted to different contexts. Each centre can use the data subset from its own centre in order to make secondary analysis. Once the main outcomes of the study are published, data access will be open to other researchers who may be interested.

The AEQUALIS study considers dimensions of participation, public involvement, ethics, gender equality, scientific education and open access included in the framework of Responsible Research and Innovation [36]. The research team will work in collaboration with an advisory committee integrated by three older women with expertise in primary care, adult education and ageing. This committee will be involved in the development of the intervention guide as well as the participant observation of its implementation. As an inequality axis, gender will be considered through all the implementation steps of the research. Although the intervention will be implemented to secure the participation of men -as they are frequently less involved in health promotion and group activities-, a major participation of women will help us to respond to the challenge of the high prevalence of older women living alone -often widows- with a poor self-perceived health and feelings of loneliness and having few opportunities to establish support ties and social networks. Data analysis will be done with men and women subgroups in order to identify possible gender differences in impacts. The research team will contact secondary education schools with the aim of making project disclosure, sensitize about health inequalities, facilitate intergenerational relationships and promote scientific education on ageing research. All publications of the project will be open access.

\section{Discussion}

This study provides a protocol for a multicentre pragmatic randomized controlled trial to assess the effectiveness of an intervention designed to promote selfmanagement, health literacy and social capital in order to improve self-perceived health in older adults living in urban disadvantaged areas. 


\section{Strengths and limitations of this study}

To the authors' knowledge, this is one of the few randomized clinical trials conducted in European cities to tackle health inequalities under a community approach [37]. It is based on a complex intervention focused on three pillars (health literacy, self-management and social capital) as potential modifiers of the influence of social determinants on health. It will test its effectiveness on increasing self-rated health in a pragmatic trial, i.e., close to the everyday practice.

Participants and professionals conducting the groupbased intervention remain unblinded, likewise blinding outcome assessors is hard to sustain due to the type of intervention. The intervention protocol is standardised in detail, including how to tailor the activities and make them participatory. In addition, the study includes a rigorous facilitator training and mentoring, which enhance the internal validity of the AEQUALIS trial.

This trial includes a process evaluation framed within the MRC guidance to assess how implementation, context and mechanisms of impact affect the outcomes. Accordingly, findings are likely to inform specific health care practices to reduce intermediate factors towards health inequalities, and thus results might be relevant clinically and from a public health perspective and useful for primary health care.

The study will provide evidence on how to implement an intervention tailored to needs and local contexts of older people living in vulnerable situations. The high capacity of tailoring the intervention to the participants and to the local context should allow the programme to be transferred to other contexts. Furthermore, qualitative methodology will help to explore how individual health and social trajectories are linked with inequalities and will provide a better understanding of values, attitudes and personal expectations on self-management, as well as health behaviours of older people in a context of social vulnerability.

The project will promote the implementation of evidence-based intervention procedures in future health policy strategies targeting older people while considering the social aspects of inequality. Indeed, at regional level, the project is aligned with the aim set out in the Catalan Health Plan 2016-2020 on reducing social inequalities measured as an increase of self-perceived health [38]. The results will provide an evidence base to set recommendations addressed to the older population, primary health care professionals and policy makers.

Finally, this project can be used as a model for its biopsychosocial perspective of health with an emphasis on salutogenesis, as a source of wellbeing and good health.

\section{Trial status}

The initial phases of this project started in March 2015. A feasibility study was performed from September 2015 until December 2015. The recruitment for the trial started in January 2016. At the time of submission of this protocol all participants have been included in the study. To date, none of the participants have completed the outcomes assessment.

\begin{abstract}
Acknowledgements
The authors would like to thank Maria Jesús Comellas, Teresa Muñoz and Assumpta Serra for their help and support during the development of the intervention guide.
\end{abstract}

\section{Funding}

The study is funded by the Programme RecerCaixa (Call 2014), a joint initiative by the Associació Catalana d'Universitats Públiques (ACUP) and Obra Social la Caixa Grant number 2014ACUP00207.

Study sponsor and funders have no role in study design; collection, management, analysis, and interpretation of data; writing of the report; and the decision to submit the report for publication.

\section{Availability of data and materials}

Not applicable.

\section{Authors' contributions}

$L C P, S B$ and RM contributed to the conception of the study. LCP, SB, XR, MR and MR collaborated to define the study protocol. LCP and SB have developed the intervention. LCP, SB and RM will coordinate the trial. LCP, SB and RM will contribute to the acquisition of the data. All authors contributed to the design of the final study and will contribute to the analysis and interpretation of data and writing of the manuscript. All authors provided feedback on the drafts of this paper and have read and approved the final manuscript.

\section{Ethics approval and consent to participate}

The study design was approved by the Clinical Investigation Ethics Committee of the IDIAP Jordi Gol.

\section{Consent for publication}

Not applicable.

Competing interests

The authors declare that they have no competing interests.

\section{Publisher's Note}

Springer Nature remains neutral with regard to jurisdictional claims in published maps and institutional affiliations.

\section{Author details}

${ }^{1}$ Fundació Salut i Envelliment UAB (Universitat Autònoma de Barcelona), Casa Convalescència. Sant Antoni Maria Claret 171, 4a planta, 08041 Barcelona, Spain. ${ }^{2}$ Institute of Biomedical Research (IIB Sant Pau), Barcelona, Spain. ${ }^{3}$ Equip d'Atenció Sardenya, EAP Sardenya, Barcelona, Spain.

Received: 12 December 2017 Accepted: 26 February 2018 Published online: 13 March 2018

\section{References}

1. Borrell C, Ru M, Pasarn Ml, Benach J, Kunst AE. La medición de las desigualdades en salud. Gac Sanit. 2000;14:20-33.

2. Borrell C, Pons-vigués $\mathrm{M}$, Morrison J, Díez È. Factors and processes in fl uencing health inequalities in urban areas 2013;67:389-391.

3. Department of Economic and Social Affairs. Population Division. World Urbanization Prospects. The 2014 Revision [internet]. N Y; 2015. Available from: https://esa.un.org/unpd/wup/Publications/Files/WUP2014-Report.pdf. Accessed 1 Mar 2018

4. Borrell C, Malmusi D, Artazcoz L, Diez E, Rodríguez-Sanz IP y. M, Campos P, et al. Propuesta de políticas e intervenciones para reducir las desigualdades sociales en salud en España. Gac. Sanit 2012;26:182-189.

5. Mackenbach JP, Bakker MJ. Tackling socioeconomic inequalities in health: analysis of European experiences. Lancet. 2003;362:1409-14. 
6. Campbell NC, Murray E, Darbyshire J, Emery J, Farmer A, Griffiths F, et al. Designing and evaluating complex interventions to improve health care BMJ [Internet] 2007;334:455-459. Available from: http://www. pubmedcentral.nih.gov/articlerender.fcgi?artid=1808182\&tool= pmcentrez\&rendertype=abstract. Accessed 1 Mar 2018.

7. Regional Office for Europe of the World Health Organization. Health 21 Health for All in the 21 st century [Internet]. Copenhagen; 1998. Available from: http://www.euro.who.int/_data/assets/pdf_file/0003/88590/EHFA5-E.pdf?ua= 1. Accessed 1 Mar 2018.

8. Regional Office for Europe of the World Health Organization. Targets for Health for All [Internet]. Copenhagen; 1985. Available from: http://www. euro.who.int/_data/assets/pdf_file/0006/109779/WA_540_GA1_85TA.pdf. Accessed 1 Mar 2018.

9. Milunpalo S, Vuori I, Oja P, Pasanen M, Urponen H. Self-rated health status as a health measure: the predictive value of self-reported health status on the use of physician services and on mortality in the working-age population. J Clin Epidemiol. 1997;50:517-28.

10. Burstrom B. Self rated health: Is it as good a predictor of subsequent mortality among adults in lower as well as in higher social classes? J. Epidemiol. Community Heal. [Internet]. 2001;55:836-40. Available from: http://jech.bmj.com/cgi/doi/10.1136/jech.55.11.836

11. Solé-Auró A, Alcañiz M. Educational attainment, gender and health inequalities among older adults in Catalonia (Spain). Int. J. Equity Health [Internet]. International Journal for Equity in Health; 2016;15:126. Available from: http:// equityhealthj.biomedcentral.com/articles/10.1186/s12939-016-0414-9

12. WHO. Ottawa charter for health promotion. Ottawa Chart. Heal. Promot. an Int. Conf. Heal. Promot. move Towar. a new public Heal. Ottawa, Geneva, Canada: World Health Organization; 1986. p. 405.

13. Eriksson $M$, Lindström B. A salutogenic interpretation of the Ottawa charter. Health Promot Int. 2008;23:190-9.

14. Shaw BA, McGeever K, Grubert E, Agahi N, Fors S. Socioeconomic inequalities in health after age 50: are health risk behaviors to blame? Soc Sci Med. 2014; 101(1):52-60.

15. Marmot M. Achieving health equity: from root causes to fair outcomes. Lancet. 2007;370:1153-63.

16. Berkman N, Sheridan S, Donahue K, Halpern D, Crotty K. Low health literacy and health outcomes: an updated systematic review. Ann Intern Med. 2011:97-107.

17. Berenguera A, Pons-Viqués M, Moreno-Peral P, March S, Ripoll J, RubioValera $\mathrm{M}$, et al. Beyond the consultation room: Proposals to approach health promotion in primary care according to health-care users, key community informants and primary care centre workers. Health Expect. [Internet]. 2017; 1-15. Available from: http://doi.wiley.com/10.1111/hex.12530\%0A, http:// www.ncbi.nlm.nih.gov/pubmed/28116774

18. Hawe P, Shiell A. Social capital and health promotion: a review. Soc Sci Med. 2000;51:871-85.

19. Moore $S$, Haines $V$, Hawe $P$, Shiell A. Lost in translation: a genealogy of the "social capital" concept in public health. J Epidemiol Community Health. 2006;60:729-34.

20. Solar O, Irwin A. A conceptual framework for action on the social determinants of health. Social Determinants of Health Discussion Paper 2 (Policy and Practice). Geneve: WHO; 2010.

21. Ministry of Health and Social Affairs. Hälsa på lika villkor: nationella mål för folkhälsan. Slutbetänkande av nationella folkhälsokommittén (Health on equal terms: final proposal on national targets for public health). Stockholm: Ministry of Health and Social Affairs; 2000 (SOU 2000:91.)

22. Putnam R. Making democracy work: civic traditions in modern Italy. Princeton: Princeton University Press; 1993

23. Nyqvist F, Forsman A. Social capital as a health resource in later life: the relevance of context. Berlin, Heidelberg: Springer; 2015.

24. Holt-Lunstad J, Smith TB, Layton JB. Social relationships and mortality risk: a meta-analytic review. PLoS Med [Internet]. 2010;7(7):e1000316. Available from: https://doi.org/10.1371/journal.pmed.1000316.

25. Kawachi I, Kennedy BP, Glass R. Social capital and self-rated health: a contextual analysis. Am. J. Public Health [Internet]. 1999;89:1187-93. Available from: http://ajph.aphapublications.org/doi/10.2105/AJPH.89.8.1187

26. Coll-Planas L, Nyqvist F, Puig T, Urrútia G, Solà I, Monteserín R. Social capital interventions targeting older people and their impact on health: a systematic review. J. Epidemiol. Community Health [Internet]. 2017;71:663 LP-672. Available from: http://jech.bmj.com/content/71/7/663.abstract

27. Blancafort S, Lobera A, González C, Ríos A, González A, Coll-Planas L. El ensayo clínico AEQUALIS para mejorar la salud autopercibida en personas mayores: evaluación de la intervención piloto Sentirnos Bien "AEQUALIS"
CLINICAL TRIAL TO IMPROVE SELF-PERCEIVED HEALTH IN OLDER PEOPLE: FEASIBILITY ASSESSMENT OF THE INTERVENTION. Comunidad [Internet]. 2017;19:4. Available from: http://comunidadsemfyc.es/el-ensayo-clinicoaequalis-para-mejorar-la-...

28. Chan A-W, Tetzlaff JM, Altman DG, Laupacis A, Gøtzsche PC, Krleža-Jerić K, et al. SPIRIT 2013 statement: defining standard protocol items for clinical trials. Ann Intern Med [Internet]. 2013;158:200-7. Available from: http:// www.ncbi.n/m.nih.gov/pmc/articles/PMC5114123/

29. Felícitas Domínguez-Berjón M, Borrell C, Cano-Serral G, Esnaola S, Nolasco A Isabel Pasarín M, et al. Construcción de un índice de privación a partir de datos censales en grandes ciudades españolas (Proyecto MEDEA). Gac Sanit [Internet] 2008;22:179-187. Available from: http://linkinghub.elsevier.com/ retrieve/pii/S0213911108712329

30. Díez E, Pasarín M, Daban F, Calzada N, Fuentes C, Artazoz L, et al. "Salut als Barris" en Barcelona, una intervención comunitaria para reducir las desigualdades sociales en salud. Comunidad. 2012;14:121-6.

31. Hoffmann TC, Glasziou PP, Boutron I, Milne R, Perera R, Moher D, et al. Better reporting of interventions: template for intervention description and replication (TIDieR) checklist and guide. Bmj [Internet]. 2014;348:g1687. Available from: http://www.bmj.com/cgi/doi/10.1136/bmj.g1687

32. Departament de Salut. Enquesta de salut de Catalunya 2012. Informe dels principals resultats [internet]. Barcelona; 2013. Available from: http:// salutweb.gencat.cat/web/.content/home/el_departament/estadistiques_ sanitaries/enquestes/02_enquesta_catalunya_continua/documents/arxius/ informeesca2012.pdf

33. Schulz KF, Altman DG, Moher D. CONSORT 2010 Statement: Updated guidelines for reporting parallel group randomised trials. J. Clin. Epidemiol. [Internet]. Schulz et al; 2010;63:834-40. Available from: https://doi.org/10. 1016/j.jclinepi.2010.02.005

34. Moore GF, Audrey S, Barker M, Bond L, Bonell C, Hardeman W, et al. Process evaluation of complex interventions: Medical Research Council guidance. Bmj [Internet]. 2015;350:h1258. Available from: http://www.bmj.com/cgi/doi/ 10.1136/bmj.h1258

35. Gale NK, Heath G, Cameron E, Rashid S, Redwood S. Using the framework method for the analysis of qualitative data in multi-disciplinary health research. BMC Medical Research Methodology [Internet]. 2013;13:117. Available from: https://doi.org/10.1186/1471-2288-13-117.

36. Bardone $\mathrm{E}$, Lind $\mathrm{M}$. Towards a phronetic space for responsible research (and innovation). Life Sci. Soc. Policy [Internet]. Berlin/Heidelberg: Springer Berlin Heidelberg; 2016;12:5. Available from: http://www.ncbi.nlm.nih.gov/pmc/articles/ PMC4875583/

37. Pons-Vigués M, Diez È, Morrison J, Salas-Nicás S, Hoffmann R, Burstrom B, et al. Social and health policies or interventions to tackle health inequalities in European cities: a scoping review. 2014;

38. Department of Health G of C. Catalonia Health Plan for 2016-2020 [Internet]. 2016. Available from: http://salutweb.gencat.cat/web/.content/ home/el_departament/Pla_salut/pla_salut_2016_2020/Documents/Pla_ salut_Catalunya_2016_2020.pdf.

\section{Submit your next manuscript to BioMed Central and we will help you at every step:}

- We accept pre-submission inquiries

- Our selector tool helps you to find the most relevant journal

- We provide round the clock customer support

- Convenient online submission

- Thorough peer review

- Inclusion in PubMed and all major indexing services

- Maximum visibility for your research

Submit your manuscript at www.biomedcentral.com/submit
Biomed Central 